811.133.1'367

811.163.41'367

811.163.41'255.4=133.1

https://doi.org/10.18485/sj.2020.25.1.13

SELENA M. STANKOVIĆ

Université de Niš

Faculté de Philosophie
Оригинални научни рад

Примљен: 15. 10. 2019.

Прихваћен: 15. 01. 2020.

\title{
SUR LA POSSESSIVITÉ DU GÉNITIF NON PRÉPOSITIONNEL DANS OSMAN DE DŽIVO GUNDULIĆ ET LES ÉQUIVALENTS FRANÇAIS ${ }^{* *}$
}

Dans ce travail, nous étudions l'emploi du génitif possessif non prépositionnel en fonction attributive dans le poème Osman de Dživo Gundulić et nous explorons ses équivalents français dans la traduction de cette œuvre épique. Autrement dit, (a) nous analysons des modèles syntaxiques de groupes nominaux à génitif possessif suivant que le génitif est employé comme forme morphologique libre ou comme celle bloquée par un déterminant obligatoire, (b) nous examinons des types sémantiques de relation possessive établie entre le possédé et le possesseur et (c) en nous servant de la méthode d'approche contrastive, nous étudions les équivalents français du syntagme possessif serbe à génitif non prépositionnel.

Mots clés : génitif non prépositionnel, possessivité, modèle syntaxique, type sémantique, langue serbe, langue française, équivalent.

*selena.stankovic@filfak.ni.ac.rs

${ }^{* *}$ La rédaction de cet article a été effectuée dans le cadre de deux projets scientifiques : La traduction dans le système de la recherche comparée des littératures et cultures serbe et étrangères $\left(\mathrm{N}^{\circ}\right.$ 178019), financé par le Ministère de l'Éducation, de la Science et du Développement technologique de Serbie, et Les langues, les littératures et les cultures romanes et slaves en contact et en divergence (NNo 81/1-17-8-01) financé par la Faculté de Philosophie de l'Université de Niš, l'Agence universitaire de la francophonie et l'Ambassade de France en Serbie. L'article représente la version élaborée et largement étendue de la communication présentée lors de la onzième édition du Colloque Les Études françaises aujourd'hui, tenu les 9 et 10 novembre 2018 à la Faculté de Philologie de l'Université de Belgrade. 


\section{INTRODUCTION}

Dans la langue serbe, parmi les moyens syntaxiques d'expression de la catégorie sémantique et logique de possession se trouve également le syntagme à génitif non prépositionnel en fonction de l'attribut ${ }^{1}$ non congruent. Le type possessif de syntagme nominal indiqué - le génitif possessif - représente une construction syntaxique fréquemment utilisée pour manifester la relation de possessivité. Il s'agit de la structure qui comprend les différentes sous-catégories sémantiques selon le sens des lexèmes en position du déterminé $2 /$ objet possédé et du déterminant/possesseur. Le système de la langue française dispose de plusieurs formes grammaticales à l'aide desquelles il dénote le rapport d'appartenance. L'une de ces formes est le groupe génitival possessif ayant un substantif comme noyau et un nom/groupe nominal comme complément du nom introduit par la préposition de $\left(\mathrm{N}_{1}+d e+\right.$ $\mathrm{N}_{2}$ ). Cette liaison syntagmatique, étant d'ailleurs en français très complexe aux plans sémantique et syntaxique, se montre apte à exprimer les diverses relations de possessivité.

Dans ce travail, nous analysons l'emploi du génitif possessif non prépositionnel en fonction attributive dans le poème épique Osman de Dživo Gundulić, le plus grand poète du baroque slave, et nous explorons ses équivalents dans la traduction française de cette œuvre. Plus précisément, notre recherche sous-entend d'abord : a) l'analyse des modèles syntaxiques de groupes substantivaux à génitif possessif adnominal suivant que le génitif, en tant qu'attribut non congruent, est employé comme forme morphologique libre ou comme celle bloquée par un déterminant obligatoire $^{3}$, et b) l'examen des types sémantiques de relation possessive établie entre l'objet d'appartenance et le sujet d'appartenance. Ensuite, nous repérons, par l'intermédiaire de l'approche contrastive, les équivalents du syntagme possessif serbe à génitif non prépositionnel adnominal dans la traduction française de ce poème de la première moitié du XVII ${ }^{e}$ siècle. Notre recherche se concentre sur le texte du Chant huitième étant donné que c'est le seul chant d'Osman de Gundulić traduit en français (1838, Antoine de Sorgo). Nous nous attendons à ce que, dans la plupart des cas, le génitif possessif serbe soit transformé en syntagme génitival $\left(\mathrm{N}_{1}\right.$ $+d e+\mathrm{N}_{2}$ ), qui s'emploie du reste pour indiquer plusieurs sortes de possession.

Pour ce faire, nous partons des définitions et des explications proposées par la littérature linguistique abordant la problématique casuelle concernée et la

${ }^{1}$ Dans ce travail, il est question de l'attribut en tant que position syntaxique dans la grammaire de la langue serbe. En français, la fonction équivalente à l'attribut serbe est l'épithète.

${ }^{2}$ Sur la terminologie employée dans cet article voir Kovačević (2015a).

${ }^{3}$ Le concept du déterminant obligatoire est entré dans la théorie linguistique grâce à la linguiste serbe Milka Ivić. Sa contribution à la définition terminologique de ce phénomène linguistique est sans doute d'une importance majeure. Sur le procédé de détermination obligatoire consulter Ivić (1959) et (2008 : 245-260), ainsi que Radovanović (1972), (1979) et (1990 : 75-113). 
question de l'expression de possessivité dans les deux langues observées. Notre exploration des types syntactico-sémantiques de construction serbe/serbocroate à génitif non prépositionnel en fonction de l'attribut non congruent se réalise suivant les interprétations théoriques, les classifications et les modèles qu'ont, pour cette catégorie grammaticale en serbe, proposés K. Feleszko (Feleško 1995) et I. Antonić (Piper et al. 2005). En même temps, nous tenons compte de la typologie sémantique des attributs non congruents à côté des noms d'objet concret établie par M. Kovačević (2015a).

\section{SUR LA POSSESSIVITÉ DU GÉNITIF NON PRÉPOSITIONNEL DANS LA LANGUE SERBE}

La possessivité, à côté des valeurs partitive et ablative, figure comme l'une des trois significations qui composent le potentiel sémantique du génitif et qui sont, avec leurs nuances de sens, toutes dérivées de la caractéristique essentielle du génitif - la désignation d'une notion à laquelle se réfère un être ou un objet marqué par le nœud du syntagme nominal (voir plus dans Belić 1998 : 164-168 ; Stevanović 1979 : 174-359). En d'autres termes, tous les usages du génitif sont découlés de « la valeur grammaticale de 'dépendance' ou de 'détermination' inhérente à la fonction syntaxique primordiale du génitif » (Benveniste 1966 : 148). Au regard de sa signification, le génitif est le cas le plus complexe, tandis que du point de vue de ses fonctions, il représente le cas le plus vaste (Stevanović 1979 : 174 ). En serbe, le cas génitif peut exprimer le rapport possessif comme génitif non prépositionnel ou comme génitif prépositionnel, à savoir : en tant que forme morphologique libre et en tant que forme bloquée soit par une préposition soit par la présence d'un déterminant obligatoire. Nous examinons l'emploi possessif de sa forme non prépositionnelle, autrement dit, de sa forme libre et de sa forme bloquée par le déterminant obligatoire. Sera étudiée, donc, la forme substantivale qui, en position du constituant subordonné/du déterminant et en fonction de l'attribut non congruent, est placée au sein du syntagme nominal dont le noyau/le déterminé est un nom marquant un objet concret.

D’après M. Kovačević (2015a : 13-27), qui s'intéresse au phénomène de l'attribut non congruent et de ses aspects syntaxiques et sémantiques en serbocroate, la possession s'avère la signification fondamentale de l'attribut non congruent qui se trouve auprès des noms indiquant un objet concret. Le syntagme possessif à génitif non prépositionnel en fonction attributive appartient à la classe de ceux qui manifestent tant la possession aliénable que la possession inaliénable ${ }^{4}$ (immanente).

${ }^{4}$ Sur le concept de possession inaliénable voir Fillmore (2003), notamment le Chapitre 5 Grammar of Inalienable Possession (89-111) dans lequel le linguiste américain expose d'une manière très 
Néanmoins, il se distingue des autres syntagmes possessifs par une plus grande liberté lexicale et par la diversité de sens possessif.

En serbe/serbocroate, le cas génitif d'un substantif est utilisé comme structure concurrente à l'attribut congruent sous forme d'un adjectif possessif ${ }^{5}$. Dans ce contexte syntactico-sémantique - la fonction attributive et la signification possessive - les formations génitivale et adjectivale se trouvent en rapport de variantes combinatoires, explique M. Ivić (1967: 262). La littérature linguistique serbe donne néanmoins l'avantage à l'adjectif possessif sur le génitif possessif (pour plus de détails sur l'emploi parallèle des deux formes possessives ainsi que sur les possibilités du choix entre elles suivant les conditions définies voir Stevanović 1939-19406 : 5-43；1979 : 182-189; Ivić 1967 ; Feleško 1995 : 37-41 ; Maretić 1963 : 565-566 ; Katičić 2002 : 47, 416-417, 445-450 ; Pavlović 1964-1965 ; Nikolić B. 1968-1969).

Dans les grammaires du serbe/serbocroate, ainsi que dans la littérature traitant la problématique casuelle, nous apercevons des différences dans l'interprétation de la catégorie de génitif possessif, c'est-à-dire dans la répartition de ses nuances de sens. Comme l'observe A. Belić (1965 : 217-222), le génitif possessif général, en tant que type de génitif génitival, inclut en même temps la signification d'appartenance au sens plus large et celle au sens plus étroit, mais aussi les génitifs subjectif et objectif. De même, ce linguiste serbe parle du caractère possessif du génitif temporel et du génitif qualitatif. Pour M. Stevanović (1979 : 175-193; 1939-1940 : 31-43), qui se penche sur l'étude d'A. Belić, la signification d'appartenance à la notion (l'être ou l'objet) dénotée par un substantif au génitif constitue la valeur générale du génitif possessif. À l'intérieur de cette valeur essentielle se développent, suivant la nature de la relation possessive, les diverses sous-espèces sémantiques : le vrai génitif possessif, les génitifs subjectif, objectif, temporel et qualitatif, les génitifs de l'origine et de la matière. Le même principe du classement des sous-catégories possessives est appliqué aussi dans la grammaire de Ž. Stanojčić (2010 : 327-328). Dans la détermination de ce type génitival, T. Maretić (1963 : 564-566) se sert de deux appellations - le génitif d'appartenance et le génitif possessif - en ne révélant pourtant ni s'il s'agit des appellations synonymes ni de quelle manière est faite la distinction entre elles. Maretić traite l'emploi parallèle de la forme génitivale du nom et de l'adjectif possessif dans le chapitre consacré au génitif possessif. La grammaire de R. Katičić (2002 : 448-465) met en relief la polysémie du génitif non prépositionnel en fonction de l'attribut non congruent. Selon l'auteur de cet

efficace le phénomène concerné en l'incluant dans les universaux du langage. À consulter aussi Herslund (1996), Riegel (1984), Karolak (1996).

${ }^{5}$ La partie du discours de la terminologie grammaticale serbe : les adjectifs dérivés d'un nom à l'aide de certains suffixes structuraux à sens possessif. La valeur fondamentale des adjectifs possessifs serbes est l'expression du rapport d'appartenance.

${ }^{6}$ L'étude la plus approfondie des attributs de sens possessif en serbocroate. 
ouvrage, les relations variées de signification possessive générale se manifestent à l'aide du génitif possessif, des génitifs du tout et du contenu, du génitif explicatif, ainsi qu'au moyen des génitifs subjectif, objectif et qualitatif.

La description la plus minutieuse du sémantisme et du fonctionnement du génitif serbocroate est proposée par le linguiste polonais Kazimierz Feleszko (Feleško 1995) dans Les significations et la syntaxe du génitif serbocroate, d'abord publié en polonais en 1970 (Sktadnia genetiwu $i$ wyrażeń przyimkowych z genetiwem w jęziku serbsko-chorwackim). Cette vaste recherche représente un apport considérable à la clarification non seulement du caractère syntactico-sémantique du génitif, mais aussi des questions relatives au système casuel dans la langue serbocroate. Sa répartition des constructions génitivales diffère d'une certaine manière de la classification traditionnelle et cela concerne particulièrement les structures à génitif sans préposition. Selon Feleszko, le génitif non prépositionnel adnominal en position attributive comprend les génitifs adverbial, qualitatif et partitif ainsi que les deux génitifs de nature possessive - le génitif possessif et le génitif d'appartenance - qui diffèrent l'un de l'autre par l'étendue de leur contenu. Le génitif possessif, signale l'auteur polonais (Feleško 1995 : 36-42), est le type génitival qui marque la relation concrète de possession entre le possesseur et le possédé et qui s'utilise parallèlement avec la formation adjectivale pour désigner le possesseur. D'après son potentiel sémantique, il représente la variante plus limitée et plus précise du second type de génitif possessif, le génitif d'appartenance. Le sémantisme de ce deuxième type génitival est en conséquence plus large et plus volumineux vu qu'il rassemble les divers rapports possessifs se réalisant entre deux êtres ou deux objets ou entre un être et un objet (les liens familiaux et sociaux, la relation de collaboration, le rapport entre la partie et le tout, etc.). Le génitif d'appartenance exprime donc les nuances variées de possessivité.

Dans le chapitre de la Syntaxe du serbe moderne: Phrase simple, consacré à la problématique syntactico-sémantique du génitif serbe, I. Antonić (Piper et al. 2005 : 144-146 ; 679-683) considère le génitif possessif comme un déterminatif possessif dont le rôle est de déterminer une notion (un être/un objet) suivant la sorte de rapport possessif : la propriété, la relation "partie-tout », la parenté, l'amitié, la coopération, l'appartenance d'une œuvre/idée à son créateur. Conformément au type de relation possessive - la possession et l'appartenance, c'est-à-dire la possession au sens plus étroit ou la possession aliénable et la possession au sens plus large ou la possession inaliénable - cette auteure distingue quelques modèles syntaxiques de syntagmes nominaux à génitif non prépositionnel (et prépositionnel) d'un substantif. 


\section{SUR LE SYNTAGME GÉNITIVAL POSSESSIF DANS LA LANGUE FRANÇAISE}

L'inventaire français des formes syntaxiques s'utilisant pour marquer le rapport d'appartenance inclut également le groupe génitival possessif présenté comme nom + de + nom/pronom. Comme le stipule J.-C. Milner (1982: 69-94) 7 , il s'agit d'une combinaison syntagmatique complexe dont le centre est un nom appartenant uniquement à la série de noms non déverbaux et laquelle peut être transformée en construction propositionnelle ayant un verbe de la classe avoir : le fils $d u$ voisin ou la maison du voisin sont paraphrasables par le voisin a un fils (la possession inaliénable) ou le voisin a une maison (la possession aliénable). Le nom tête du groupe complexe se distingue par la forme définie et l'emploi de l'article indéfini est acceptable exclusivement à condition que l'interprétation soit partitive et, dès lors, paraphrasable par un des fils du voisin. Le constituant subordonné à l'intérieur de ce lien syntagmatique est un groupe nominal qui assume la fonction du complément du nom et qui est introduit par la préposition $d e$. Quant à la préposition de, elle se définit comme un de casuel, autrement dit, comme une marque casuelle puisque par ex. dans la structure la maison de Pierre « de est la réalisation segmentale d'un cas, qu'on appellera le Génitif. Ce cas est assigné à un Nom" dépendant directement, sans préposition, d'un autre N" [...] Le cas génitif est assigné à Pierre et se réalise comme de » (Ibid. : 83). En français, souligne Milner (Ibid. : 95), ce complément génitival ou le génitif possessif, un des types de génitif adnominal français, représente un syntagme nominal fléchi.

La liaison de ce type structural $\left(\mathrm{N}_{1}+d e+\mathrm{N}_{2}\right)$ se prête à l'expression de l'appartenance grâce à la capacité syntactico-sémantique de la préposition de qui, d'après A. Dauzat (1956 : 354-357), pendant l'évolution de la langue française a commencé à assumer les fonctions du génitif latin dont l'un des traits essentiels est la possession. Certains linguistes (Benveniste 1966 : 145 ; Wagner, Pinchon 1962 : 69 ; NPR 1996 : 536 s.v. de) mettent en évidence que ladite union génitivale exprime la relation d'appartenance, tandis que d'autres avancent qu'elle manifeste également la possession comme une des valeurs rassemblées à l'intérieur de la signification d'appartenance (TLFi 2018 : s.v. de ; Gardes Tamine 2012 : 203). Dans son article sur les relations appelées l'appartenance et la possession, M. Riegel (1984) souligne pourtant qu'il est question, en effet, d'un même rapport dont la dénomination dépend de l'ordre des éléments reliés. L'auteur parle des trois types de relation d'appartenance - l'appartenance de la partie à une entité conçue comme le tout (l'appartenance partitive), l'appartenance du membre à une classe (l'appartenance ensembliste) et l'appartenance de l'objet possédé à son possesseur

${ }^{7}$ Sur les différences des génitifs - le type Possessif, le type Agent et le type Objet - et leurs combinaisons, sur la nature du génitif possessif, sa structure et ses particularités syntaxiques voir dans Milner (1982 : 69-122). 
(l'appartenance/la possession) - et décrit leurs caractéristiques sémantico-logiques. Selon lui, la construction prépositionnelle $\mathrm{N}_{1}+d e+\mathrm{N}_{2}$ se montre apte à exprimer toutes les trois relations voisines d'appartenance. En examinant le concept d'appartenance et le syntagme nominal dont l'élément subordonné a la forme génitivale $(d e+\mathrm{N})$, S. Karolak (1996) explique, pareillement à Riegel, que les deux termes - l'appartenance et la possession - relèvent d'une même catégorie de sens ; les termes démontrent, en fait, quel est l'ordre des noms/groupes nominaux désignant le sujet d'appartenance et l'objet d'appartenance, plus précisément si c'est le possesseur ou le possédé qui est le thème ou le rhème de la structure communicative de la phrase.

Dans le cadre de sa recherche des possibilités morphologiques et sintaxiques pour l'expression de la possessivité en français, V. Roglić (2001 : 34-35) renvoie aux conclusions de J.-C. Milner (1982) en soulignant que la liaison génitivale possessive équivaut à l'adjectif possessif et au syntagme verbal à avoir. Ainsi, la valeur possessive du groupe substantival est confirmée : a) par la tranformation du lien $d e+n o m$ en déterminant possessif ${ }^{8}$ (la maison de Pierre $\rightarrow$ sa maison) ${ }^{9}$, de même que b) par la transposition du syntagme nominal dans le groupe comportant le verbe avoir (la maison de Pierre $\rightarrow$ Pierre a une maison.).

La linguistique française avance qu'au moyen de la combinaison syntagmatique possessive à complément génitival s'expriment les différentes catégories de possessivité suivant les valeurs référentielles des noms en question : la possession d'un objet par un sujet humain, le rapport entre une entité et sa partie constitutive, les liens de famille, d'amitié et d'hostilité, la relation de collaboration, les rapports officiels et d'affaires, la relation de paternité d'une œuvre/idée, etc. (Milner 1982 : 69-122 ; Roglić 2001 : 34-40 ; TLFi 2018 : s.v. de ; Chevalier et al. 1964 : 187 ; Riegel et al. $2011: 644$; Wilmet $2010: 453$ ).

\section{SUR OSMAN ET SA TRADUCTION FRANÇAISE}

Notre analyse de l'emploi du génitif possessif adnominal s'effectue sur les exemples tirés d'Osman, le poème le plus beau du baroque slave et l'ouvrage le plus considérable dans la littérature créée en langue littéraire de Dubrovnik. Le Ragusain Dživo Gundulić (1589-1638), le plus grand poète du baroque non seulement

${ }^{8}$ Les circonstances de l'alternance du possessif et du complément de nom du type de + nom/ groupe nominal, les questions du rapport entre ces deux formes à valeur possessive, ainsi que les particularités du complément de nom mentionné sont examinées en détail sur les plans syntaxique et sémantique par la linguiste D. Godard (1986). Sur ce phénomène linguistique consulter aussi Kupferman (1996).

${ }^{9}$ Sur la différence entre la structure du type $\mathrm{N}_{1}+d e+\mathrm{N}_{2}$ et le syntagme à possessif, deux formes pour manifester la relation d'interdépendance, lire dans Charaudeau (1992 : 191-194). 
yougoslave, mais aussi slave, écrivait cette œuvre au cours de la première moitié du XVII ${ }^{e}$ siècle afin de lui donner sa forme définitive en 1638 - l'œuvre compte vingt chants dont les deux au milieu, le quatorzième et le quinzième, manquent (Pantić 1967). L'expression poétique du poème épique de Gundulić est la langue littéraire ragusaine basée sur le dialecte štokavien de l'Herzégovine de l'Est. ${ }^{10}$

Dans le présent travail, nous examinons le texte du Chant huitième puisque c'est le seul chant d'Osman de Gundulić traduit en français. L'auteur de la traduction est Antoine (de) Sorgo ou Antun Sorkočević, le Comte de Sorgo (1775-1841), diplomate, écrivain et compositeur ragusain, francophile et dernier représentant de la République de Dubrovnik en France (Maixner 1955 : 27-31 ; Sorkočević 2018 : http://www.enciklopedija.hr/natuknica.aspx?ID=57209 ; Pavlović 1995 : 104-105 $)^{11}$. Sa traduction fragmentaire du poème a été éditée pour la première fois en 1838 au sein de l'essai Osman, Poëme illyrien, en 20 chants de trente-quatre pages dans la Revue du Nord ( $\mathrm{N}^{\circ} 8$, de 1838). L'année suivante, Sorgo a fait paraître le même texte, comme un Extrait de la Revue du Nord, dans son livre Fragments sur l'histoire politique et littéraire de l'ancienne République de Raguse et sur la langue slave (Paris, 1839) réunissant plusieurs brochures de l'auteur. Au bout de l'introduction de son texte, le comte de Sorgo expose la raison de son choix des fragments pour la traduction : « [...] nous donnerons le faible essai d'une traduction d'une partie de l'épisode qui nous a paru le plus original et, le plus intéressant parce qu'il se rattache à l'histoire nationale de la Servie » (Sorgo $1839: 17$ ).

L'original serbe du Chant huitième contient sept-cent-soixante-seize vers, écrit en octosyllabe et en quatrains, alors que la version française comprend quatre-cent-vingt-quatre vers $(1-28,73-124,161-264,345-440,589-732)$ avec les constructions donnant souvent une traduction assez libre. Les segments non traduits du Chant huitème sont brièvement relatés soit en une phrase soit en plusieurs phrases dans les parenthèses.

${ }^{10}$ Pour plus de details sur la langue littéraire ragusaine, son origine et son alphabet, sur ses systèmes phonétique et morphologique, sur son lexique, ses caractéristiques archaïques (tant dans sa structure grammaticale que dans son fond lexical), ainsi que sur les auteurs qui écrivaient en langue de la République de Raguse voir dans Milanović (2010 : 65-76).

${ }^{11}$ Antoine Sorgo, le Ragusain qui est devenu Parisien, et Marc Bruère Desrivaux ou Mark-Brijer Derivo ou Marko Bruerović/Bruerović (vers 1770-1823), le Français qui est devenu Ragusain, le poète croate d'origine française, représentent les deux symboles des rapports culturels entre la France et Dubrovnik (Pavlović 1994 : 45, 52 ; 1995 : 104-105 ; Bruerević 2018 : http://www.enciklopedija. hr/Natuknica.aspx?ID=9803). Pour savoir plus sur la vie de Sorgo et son œuvre littéraire, sur sa carrière diplomatique et son rôle historique de l'envoyé de la République auprès de Napoléon, consulter Maixner (1955), Vojnović (1908 : I 369-376, II 37-56), Deanović (1950 : 75-78). 


\section{ANALYSE DU CORPUS}

\subsection{Le génitif possessif non prépositionnel : modèle syntaxique et type sémantique}

L'examen de notre corpus linguistique - le classement des constructions syntaxiques à génitif adnominal et la détermination de la nature sémantique du rapport possessif entre le possesseur et le possédé - montre que dans le Chant huitième d'Osman apparaissent les différentes espèces de syntagmes non congruents à génitif possessif non prépositionnel en fonction attributive. Notre matériel serbe comprend au total les dix-neuf exemples de syntagme casuel observé à l'intérieur desquels les positions du déterminé/le possédé et du déterminant/le possesseur sont occupées par des lexèmes sémantiquement variés. De leur diversité provient un vaste spectre de significations possessives embrassant tous les deux types sémantiques de possessivité (les possessions inaliénable et aliénable). Ainsi, la langue du poème épique Osman est marquée par les types syntactico-sémantiques suivants de syntagme à génitif possessif adnominal :

a) la construction casuelle possessive qui manifeste un modèle d'appartenance au sens plus large - la relation entre une entité et sa partie constitutive. La position de l'élément subordonné du syntagme (le déterminant/le possesseur) est occupée par la forme génitivale du substantif désignant un tout auquel appartient la notion indiquée par le noyau du syntagme (le déterminé/le possédé). Le génitif en fonction attributive a la forme morphologiquement libre. Le déterminé est, lui aussi, conçu comme le tout. Cette combinaison syntagmatique comprend les deux sous-espèces. L'une est la structure possessive de caractère somatique étant donné qu'elle annonce l'appartenance d'une partie corporelle à son tout/au corps :

(1) Рајски урес лища твога / кй моћ изрит није бесједом [...]. (OS33$34)^{12}$

(2) [...] још сред уста љута Змаја / и ноката бијесна Лава [...]. (OS577578)

(3) [...] уграби ју он по сили / исприд скута ћаћка слијепа [...]. (OS607608)

(4) [...] руке бијеле и снјежане / милостиве кћерие своје. (OS111-112)

La seconde est la structure possessive non somatique puisqu'elle exprime l'appartenance d'une partie intégrale à un objet matériel ou à une construction physique ou à une notion abstraite :

(5) [...] и незнане пуке трави / у најдаљијех странах свита. (OS27-28)

(6) Шатори су извезени / зеленога дубја китје [...]. (OS105-106)

${ }^{12}$ Entre les parenthèses, derrière le sigle référant à l'original d'Osman (OS) se trouvent les numéraux des vers du poème. 
(7) [...] и у погледу ње објави / тајчас му се сунчја зрака. (OS359-360)

(8) Под звјездами твога уреса / ни је било, ни ће бити [...]. (OS57-58)

$\mathrm{Vu}$ le sémantisme de deux constituants du groupe génitival, le lien qui existe entre le possesseur et l'objet possédé peut se présenter, suivant les modèles définis dans la littérature linguistique (Feleško 1995 : 41-42), comme le lien du type un être humain/un animé + un objet ou du type $u n$ objet + un objet. La construction qui dénote la relation "partie-tout» s'avère le type le plus fréquent de génitif possessif dans le corpus analysé (au total 14 exemples).

b) le groupe nominal possessif qui désigne la possessivité relationnelle en tant que catégorie d'appartenance au sens plus large. Plus précisément, dans notre corpus il s'agit de différentes relations de parenté. Le substantif, sous forme génitivale bloquée par le déterminant obligatoire, se comporte comme attribut non congruent (le déterminant/le possesseur) en actualisant le nom qui tient la place du centre du groupe (le déterminé/le possédé). Cette combinaison syntagmatique symbolise l'union du type un être humain/un animé + un être humain/un animé :

(9) [...] кй се унука̂ унук зове / Ђурђа деспота и Јерине [...]. (OS81-82)

Dans le matériel analysé, nous dégageons également l'emploi morphologiquement libre du génitif possessif du nom propre :

(10) [...] кличе третји, к Задру упути / Ђурађ деспот за на прика / зета Угре подигнути [...]. (OS326-328)

(11) Јур је дошо̂ Казлар-ага / к Смедерову бијелу граду, / за изнаћи кћер љубдрага [...]. (OS73-75)

De fait, il est question ici de la situation en langue serbe qui permet l'apparition parallèle des formations adjectivale et génitivale des noms propres et communs. C'est l'indication individuelle et l'énumération des êtres humains auxquels appartient la notion désignée par le centre du syntagme. L'usage noté du génitif possessif peut être justifié aussi par l'intention du poète de répondre à l'exigence de la versification (voir Stevanović 1939-1940 : 5-43 ; 1979 : 183-188 ; Nikolić B. 1968-1969 ; Feleško 1995 : 37-40).

c) la structure syntaxique possessive qui évoque une sorte d'appartenance au sens plus large - le rapport de paternité d'une œuvre ou d'une idée. La fonction du constituant principal du syntagme nominal (le déterminé/le possédé) est assurée par le nom indiquant une notion qui, étant une création ou une œuvre, appartient à son créateur. Le constituant subordonné attributif du syntagme (le déterminant/le possesseur) se trouve au cas génitif bloqué par la présence du déterminant obligatoire ; il assume la fonction de l'attribut non congruent et joue le rôle sémantique de l'auteur de l'œuvre. Dans l'exemple extirpé, l'omission de déterminant obligatoire auprès du génitif possessif du nom propre s'explique par les besoins de versification : 
(12) Запопијева други опета / ко̂ Биограду помоћ пода / према силам Maхумета [...]. (OS317-319)

À l'intérieur de la construction concernée, le rapport entre le possesseur et le possédé figure comme lien du type un être humain/un animé + un objet. C'est le modèle de possessivité inaliénable qui se montre le moins fréquent - nous n'en dégageons qu'une occurrence.

d) le syntagme nominal possessif qui signifie l'appartenance au sens plus étroit, c'est-à-dire la possession aliénable - la relation de propriété. Le noyau de la combinaison syntagmatique (le déterminé/le possédé) est le substantif désignant une notion qui, en tant que propriété, appartient à son propriétaire. La position subordonnée attributive (le déterminant/le possesseur) est occupée par le génitif non prépositionnel bloqué par le déterminant obligatoire, comme le suit dans notre corpus :

(13) [...] и како се испод мира̂ / града тога цар охоли / љуто рањен тад истира [...]. (OS321-323)

\subsection{L'emploi stylistique de la construction}

Notre recherche révèle aussi l'emploi stylistique de cette structure casuelle. En effet, dans la disposition sémantico-grammaticale des constituants d'un syntagme substantival, l'attribut non congruent se trouve normalement postposé au substantif, explique M. Kovačević (2015a : 16-17) ${ }^{13}$, en concluant ensuite que la postposition et le contact du déterminant avec le déterminé font parfois le seul indice de sa fonction attributive. En conséquence, chaque fois que ce type de génitif non prépositionnel adnominal apparaît antéposé au centre du lien syntagmatique, l'ordre des mots, étant modifié, devient marqué. La permutation de l'attribut non congruent (voir Kovačević 2015b : 331-332) suscite une couleur stylistique du syntagme nominal car la qualité de la notion désignée par le substantif s'accentue aux plans communicatif et émotionnel. Plusieurs exemples du corpus analysé illustrent ce procédé stylistique :

(14) [...] а без свитлости и без плама / лијепијех се очи поглед скрати! (OS279-280)

(15) [...] и љубљеним синовима, / кй бише очи мојих зенище [...]. (OS625-626)

(16) Шатори су извезени / зеленога дубја китје [...]. (OS105-106)

(17) [...] кй се унука̂ унук зове / Ђурђа деспота и Јерине [...]. (OS81-82)

(18) Ти по свакој свијета страни / гледаш, мајко, на дан био [...]. (OS489490)

13 Sur la linéarisation en tant qu'un des moyens les plus importants d'exprimer la stratégie communicative du locuteur et la perspective communicative de la phrase voir aussi Piper et al. (2005 : 1072-1081). 


\subsection{Les équivalents français du génitif possessif non prépositionnel serbe}

L'étude de la version française du Chant huitième d'Osman montre en premier lieu que dans le texte de la traduction, étant incomplète, nous notons les dix équivalents de la construction casuelle observée. Notre exploration fait voir en second lieu que dans la version française du poème, le génitif non prépositionnel serbe à valeur possessive et à fonction attributive se transforme le plus souvent en forme syntaxique équivalente, c'est-à-dire en génitif possessif. D'une grande capacité sémantique, le groupe génitival français indique une gamme de significations possessives variées. Ainsi, la plus grande partie des exemples avec le génitif concerné de l'original serbe obtient pour son équivalent français le syntagme génitival possessif qui évoque :

- l'appartenance d'une partie intégrale à son tout, soit qu'il s'agisse du type somatique de possession :

(19) [...] вид жуђени и зеница / слијепа стариа, ћаћка свога [...]. (OS79-80) - [...] la prunelle des yeux, la lumière désirée de son père aveugle [...]. $(\mathrm{OF} 19)^{14}$

(20) [...] руке бијеле и снјежане / милостиве кћерие своје. (OS111-112) - Et plus blanches que la neige, les mains de sa douce fille [...]. (OF20)

(21) [...] уграби ју он по сили / исприд скута ћаћка слијепа [...]. (OS607608) - Il arracha avec violence des bras de son père aveugle la belle et vertueuse fille. (OF25)

(22) [...] и љубљеним синовима, / кй бише очи мојих зенице [...]. (OS625$626)$ - [...] pour les enfans qui étaient la prunelle de mes yeux. (OF25)

Ou bien qu'il s'agisse de la possessivité de caractère non somatique :

(23) [...] и у погледу ње објави / тајчас му се сунчја зрака. (OS359-360) $-[\ldots]$ et son regard fut pour lui un rayon du soleil. $(\mathrm{OF} 23)^{15}$

(24) Шатори су извезени / зеленога дубја китје [...]. (OS105-106) - Les voûtes verdoyantes des arbres remplacent ses tentes brodées [...]. (OF20)

- les diverses relations familiales en tant que sorte de possession inaliénable :

(25) Јур је дошоิ Казлар-ага / к Смедерову бијелу граду, / за изнаћи кћер Љубдрага [...]. (OS73-75) - Déjà le Kislar-Aga a atteint la blanche ville de Semendria où il espère trouver la fille de Liubdrag [...]. (OF19)

\footnotetext{
${ }^{14}$ Entre les parenthèses, derrière le sigle qui réfère à la traduction de Sorgo d'Osman (OF) sont donnés les numéraux des pages sur lesquelles se trouve la traduction des vers du Chant huitième.

${ }^{15} \mathrm{C}$ 'est le seul exemple de notre corpus français où apparaît la forme indéfinie du pivot du syntagme laquelle, dès lors, se réfère à l'interprétation partitive du pivot.
} 
(26) [...] кй се унука̂ унук зове / Ђурђа деспота и Јерине [...]. (OS81-82) - Qui s'appelle le neveu des neveux de George Despote et de Jérine [...]. (OF19)

Outre ledit moyen syntaxique qui domine dans le matériel recherché, pour transférer le groupe possessif serbe, A. Sorgo, l'auteur de la traduction française du poème Osman se sert de la construction qui associe la traduction plus libre avec le déterminant possessif, une forme morphologique dont la signification primaire est l'appartenance ${ }^{16}$ :

(27) Све најлипше губе име / прид уресом юе уреса [...]. (OS233-234) - Toutes les plus belles filles perdent leur renom devant l'éclat qu'elle répand sur sa parure [...]. (OF21)

Donc, à l'intérieur de la traduction plus libre, en employant le possessif le traducteur français souligne la possessivité contenue dans le vers serbe et réussit, par conséquent, à garder l'intention expressive de l'original.

Enfin, dans notre corpus français, le syntagme possessif serbe à génitif adnominal se réalise également comme la construction qui représente une traduction plus libre :

(28) [...] у великој тере слави / лети свуда гласовита / и незнане пуке трави / у најдаљијех странах свита. (OS26-28) - Sa renommée vole alors les ailes d'une gloire immense et charme les peuples les plus inconnus. (OF18-19)

\section{CONCLUSION}

La recherche effectuée démontre que le Chant huitième du poème épique Osman contient les dix-neuf exemples du syntagme substantival possessif à génitif non prépositionnel. Dans ce groupe nominal, les fonctions du déterminé/le possédé et du déterminant/le possesseur sont assurées par les unités lexicales sémantiquement variées. Il en résulte la présence de tous les deux types sémantiques de rapport possessif: la possession inaliénable (очи мојих зенице, уста љута 3маја, у најдаљијех странах свита, под звјездами твога уреса, кћер Љубдрага, зета Угре, према силам Махумета, etc.) et la possession aliénable (испод мира града тога). Nous constatons la prévalence des constructions dénotant la possession inaliénable.

${ }^{16}$ Sur la question des morphèmes de la catégorie du possessif cf. Roglić (2001 : 17-24). Pour plus de détails sur l'emploi du déterminant possessif voir Gary-Prieur (2011). À propos des trois séries d'expressions possessives (les possessifs déterminatifs, les possessifs adjectivaux et les possessifs datifs), de leurs formes, particularités structurelles, valeurs d'emploi, ainsi que des possibilités pour leur combinaison lire dans Zribi-Hertz 1999. Sur les déterminants possessifs consulter aussi Riegel et al. (2011 : 288-290), Arrivé et al. (1986 : 545-548) ; Wagner, Pinchon (1962: 80-84), Grevisse (1993 : 907-917). 
En ce qui concerne les modèles syntactico-sémantiques de syntagme, notre analyse découvre le suivant :

a) les structures casuelles évoquant la relation " partie-tout» sont les plus fréquentes - les quatorze occurrences dont les neuf exprimant la possession somatique et les cinq marquant la possession non somatique ; le génitif, en position du déterminant/le possesseur et en fonction de l'attribut non congruent, s'emploie comme forme morphologiquement libre ;

b) les trois occurrences du groupe nominal possessif manifestant les liens de parenté comme catégorie de possession inaliénable. Le substantif au génitif adnominal, qui se comporte en déterminant/possesseur et assume la fonction attributive, est utilisé sous forme bloquée par le déterminant obligatoire, mais également sous forme libre (du nom propre) ;

c) la construction à génitif désignant le rapport de paternité d'une œuvre, en tant qu'une des sortes de possession inaliénable, apparaît une seule fois. Sa particularité dans notre matériel est l'absence du déterminant obligatoire à côté du génitif (le déterminant/le possesseur) du nom propre ;

d) une seule occurrence de syntagme nominal à génitif non prépositionnel exprimant la relation de propriété comme type de possession aliénable. La forme génitivale qui fonctionne comme déterminant et sujet d'appartenance s'emploie bloquée par le déterminant obligatoire ;

e) l'expression linguistique du poème Osman est marquée par l'usage stylistique du génitif possessif non prépositionnel.

Quant aux équivalents français du syntagme possessif à génitif non prépositionnel dans le corpus étudié, il s'agit le plus souvent de la structure génitivale possessive $\left(\mathrm{N}_{1}+d e+\mathrm{N}_{2}\right)$. Ceci signifie que notre hypothèse de départ est prouvée. Dans les exemples extraits, ce lien syntagmatique annonce l'appartenance d'une partie (intégrale) à une entité conçue comme le tout (la possession somatique et non somatique), ainsi que la relation de parenté. Outre la construction à génitif possessif, le traducteur d'Osman de Gundulić en langue française utilise aussi les structures qui représentent la traduction plus libre combinée parfois avec le déterminant possessif.

\section{SOURCES}

OF : Antoine de Sorgo, Fragments sur l'histoire politique et littéraire de l'ancienne République de Raguse et sur la langue slave, Paris : Imprimerie de Madame Porthmann, 1839.

OS : Џиво Гундулић, Осман, приредио Мирослав Пантић, Београд: Српска књижевна задруга, 1967. 


\section{BIBLIOGRAPHIE}

Arrivé et al. 1986: M. Arrivé, F. Gadet, M. Galmiche, La grammaire d'aujourd'hui: guide alphabétique de linguistique française, Paris: Flammarion.

Belić 1965: А. Белић, Историја српскохрватског језика, књ. II, св. 1: Речи са деклинацијом (Предавања др Александра Белића), 2. издање, Београд: Научна књига.

Belić 1998: А. Белић, О језичкој природи и језичком развитку, књ. I и II, у: Изабрана дела, Први том: Општа лингвистика, Београд: Завод за уџбенике и наставна средства.

Benveniste1966: É. Benveniste, Problèmes de linguistique générale I, Paris: Éditions Gallimard.

Bruerević 2018: Bruerević, Marko. Hrvatska enciklopedija. <http://www. enciklopedija.hr/Natuknica.aspx?ID=9803>. 2. X 2018.

Charaudeau 1992: P. Charaudeau, Grammaire du Sens et de l'Expression, Paris: Hachette.

Chevalier et al. 1964: J.-C. Chevalier, C. Blanche-Benveniste, M. Arrivé, J. Peytard, Grammaire Larousse du français contemporain, Paris: Larousse.

Dauzat 1956: A. Dauzat, Grammaire raisonnée de la langue française, $4^{\mathrm{e}}$ édition, Lyon: IAC.

Deanović 1950: M. Deanović, Anciens contacts entre la France et Raguse, Zagreb: Institut français de Zagreb.

Feleško 1995: К. Фелешко, Значења и синтакса српскохрватског генитива, с пољског превела Гордана Јовановић, Београд: Вукова задужбина; Нови Сад: Матица српска, Орфелин.

Fillmore 2003: Ch. J. Fillmore, Form and Meaning in Language, Volume 1, Papers on Semantics Roles, Stanford, CA: CSLI Publications, 21-119.

Gardes Tamine 2012: J. Gardes Tamine, La Grammaire - Syntaxe, Tome 2, $5^{\mathrm{e}}$ édition, Paris: Armand Colin.

Gary-Prieur 2011: M.-N. Gary-Prieur, Les déterminants du français, Paris: Éditions Ophrys.

Godard 1986: D. Godard, Les déterminants possessifs et les compléments de nom, Langue française, 72, 102-122.

Grevisse 1993: M. Grevisse, Le bon usage : grammaire française, Refondu par André Goosse, Paris: Éditions Duculot. 
Herslund 1996: M. Herslund, Partitivité et possession inaliénable, Faits de langues, 7 (Mars 1996), La relation d'appartenance, 33-42.

Ivić 1959: М. Ивић, Српскохрватски падежни облици обавезно праћени одредбом као помоћним морфолошким знаком, Годишњак Филозофског факултета у Новом Саду, IV, 151-163.

Ivić 1967: M. Ivić, Genitivne forme srpskohrvatskih imenica i odgovarajuća pridevska obrazovanja sufiksom -ov (-ev, -ovljev, -evljev), -in u odnosu „kombinatiričnih varijanata”, Годишњак Филозофског факултета у Новом Саду, X, 257-262.

Ivić 2008: M. Ivić, Iz padežne problematike, in: Lingvistički ogledi, Beograd: Biblioteka XX vek.

Karolak 1996: S. Karolak, Considérations sur le concept d'appartenance, Faits de langues, 7, 101-110.

Katičić 2002: R. Katičić, Sintaksa hrvatskoga književnog jezika, Zagreb: Hrvatska akademija znanosti i umjetnosti, Nakladni zavod Globus.

Kovačević 2015a: М. Ковачевић, Кроз синтагме и реченице, Београд: Јасен.

Kovačević 2015b: М. Ковачевић, Стилистика и граматика стилских фигура, IV битно допуњено издање, Београд: Јасен.

Kupferman 1996: L. Kupferman, Les génitifs : gouvernement d'antécédent et gouvernement thématique, Langue française, 109, 104-125.

Maixner 1955: R. Maixner, Književni dodiri i veze Antuna Sorga-Sorkočevića, Rad JAZU, 304 (1955), 5-36.

Maretić 1963: T. Maretić, Gramatika hrvatskoga ili srpskoga književnog jezika, Treće, nepromijenjeno izdanje, Zagreb: Matica Hrvatska.

Milanović 2010: А. Милановић, Кратка историја српског књижевног језика, Београд: Завод за уџбенике.

Milner 1982: J.-C. Milner, Ordres et raisons de langue, Paris: Éditions du Seuil.

Nikolić 1968-1969: М. Б. Николић, О посесивном генитиву личних имена, Наш језик, XVII, 264-283.

NPR 1996: P. Robert, Le Nouveau Petit Robert. Dictionnaire alphabétique et analogique de la langue française, Nouvelle édition du Petit Robert de Paul Robert, Texte remanié et amplifié sous la direction de Josette Rey-Debove et Alain Rey, Paris: Dictionnaires Le Robert.

Pavlović 1964-1965: М. Павловић, Посесивни генитив и присвојни придев, Наш језик, XIV, 235-238. 
Pavlović 1994: М. Б. Павловић, Од Есклавоније ка Југославији, Сремски Карловци-Нови Сад: Издавачка књижарница Зорана Стојановића.

Pavlović 1995: М. Павловић, Дубровник у француској књижевности, Зборник Матице српске за књижевност и језик, књ. 43, св. 1 (1995), 95-119.

Pantić 1967: М. Пантић, Предговор, Поетика Гундулићевог „Османа”, in: Џ. Гундулић, Осман, приредио Мирослав Пантић, Београд: Српска књижевна задруга, VI-LIII.

Piper et al. 2005: П. Пипер, И. Антонић, В. Ружић, С. Танасић, Љ. Поповић, Б. Тошовић, Синтакса савременога српског језика: проста реченица, у редакцији Милке Ивић, Београд: Институт за српски језик САНУ, Београдска књига; Нови Сад: Матица српска.

Radovanović 1972: M. Radovanović, Opštelingvistički aspekt kategorije „obavezni determinator" u sintaksi, Годишьак Филозофског факултета у Новом Саду, XV/1, 211-240.

Radovanović 1979: M. Radovanović, Gramatika neotuđive posesije: neki slučajevi s implicitnim obaveznim determinatorom u srpskohrvatskom jeziku, Зборник за филологију и лингвистику, XXII/1, 17-23.

Radovanović 1990: M. Radovanović, Spisi iz sintakse i semantike, Sremski Karlovci: Izdavačka knjižarnica Zorana Stojanovića; Novi Sad: Dobra vest.

Riegel 1984: M. Riegel, Pour une redéfinition linguistique des relations dites de "possession" et d"'appartenance", L'Information Grammaticale, $23,3-7$.

Riegel et al. 2011: M. Riegel, J.-Ch. Pellat, R. Rioul, Grammaire méthodique du français, Paris: Presses Universitaires de France.

Roglić 2001: V. Roglić, Posesivne kategorije i konstrukcije u francuskom jeziku, Beograd: Mrlješ.

Sorgo 1839: A. de Sorgo, Fragments sur l'histoire politique et littéraire de l'ancienne République de Raguse et sur la langue slave, Paris: Imprimerie de Madame Porthmann.

Sorkočević 2018: Sorkočević, Antun. Hrvatska enciklopedija. <http://www. enciklopedija.hr/natuknica.aspx?ID=57209>. 2. X 2018.

Stanojčić 2010: Ж. Станојчић, Граматика српског књижевног језика, Београд: Креативни центар. 
Stevanović 1939-1940: М. Стевановић, Посесивне форме у српскохрватском језику, Годишњак Скопског филозофског факултета, IV/1, Скопље, 1-50.

Stevanović 1979: М. Стевановић, Савремени српскохрватски језик: граматички системи и књижевнојезичка норма II, Синтакса, III издање, Београд: Научна књига.

TLFi 2018: Le Trésor de la langue française informatisé. <http://www.atilf.fr/tlfi>. 29. IX 2018, 3. X 2018.

Vojnović 1908: Dr L. K. Vojnović, Pad Dubrovnika, I (1797-1806), II (1807-1815), Zagreb.

Wagner, Pinchon 1962: R. L. Wagner, J. Pinchon, Grammaire du français classique et moderne, Édition revue et corrigée, Paris: Librairie Hachette.

Wilmet 2010: M. Wilmet, Grammaire critique du français, $5^{\mathrm{e}}$ édition entièrement revue, Louvain-la-Neuve: De Boeck / Duculot.

Zribi-Hertz 1999: A. Zribi-Hertz, Le système des possessifs en français standard moderne, Langue française, 122, 7-29.

О ПОСЕСИВНОСТИ БЕСПРЕДЛОШКОГ ГЕНИТИВА У ОСМАНУ ЏИВА ГУНДУЛИЋА И ФРАНЦУСКИМ ЕКВИВАЛЕНТИМА

\section{Резиме}

У раду се, на материјалу из епа Осман Џива Гундулића, испитује употреба посесивног беспредлошког генитива у функцији неконгруентног атрибута у српском језику. Методом контрастивне анализе, на грађи из француског превода, разматрају се еквиваленти српске супстантивне синтагме са датим генитивним типом. Синтаксичко-семантичка анализа показала је следеће:

a) у склопу структуре са посесивним адноминалним генитивом на позицијама детермината/посесума (тј. главног члана синтагме) и детерминанта/посесора (тј. генитива у служби неконгруентног атрибута) забележене су лексеме различитог значењског садржаја и обе семантичке врсте припадања, својом фреквентношћу нарочито се истиче релација неотуђивог карактера;

б) најфреквентнија синтаксичко-семантичка конструкција је падежни склоп којим се исказује однос дела према целини, и то као соматски, али и несоматски тип посесивности; генитив се уз именицу појављује као слободна морфолошка форма;

в) у оквиру неотуђиве посесије у грађи су уочене и супстантивне синтагме за означавање родбинског односа као подврсте релационе посесивности, при чему је 
адноминални генитив везан обавезним детерминатором или је пак употребљен као слободна падежна форма властитог имена, као и генитивна конструкција којом се изражава припадање по ауторству и коју карактерише одсуство обавезног детерминатора уз генитив личног имена;

г) присутна је генитивна веза за исказивање припадничко-поседничког односа (власништва), као тип посесивности отуђиве природе; уз именицу стоји генитивна форма блокирана обавезним детерминатором;

д) супстантивна синтагма са беспредлошким генитивом, услед пермутације неконгруентног атрибута, појављује се као стилистички обојена категорија;

ђ) у француском преводу Гундулићевог Османа анализирани српски генитивни склоп најчешће се преноси еквивалентим обликом, односно конструкцијом са посесивним генитивом којом су обележене припадност дела целини соматског и несоматског типа и различите врсте родбинских релација. Осим тога, преводилац се служи и структурама које представљају слободни превод а које повремено комбинује са присвојним детерминативом.

Кључне речи: беспредлошки генитив, посесивност, синтаксички модел, семантички тип, српски језик, француски језик, еквивалент.

Селена М. Станковић 